\title{
LIDERANÇA GERENCIAL: UMA ANÁLISE COM BASE NA MOTIVAÇÃO E GESTÃO DE PESSOAS
}

\section{ARTIGO ORIGINAL}

VIEIRA, Maycon William Gemaque ${ }^{1}$

VIEIRA, Maycon William Gemaque. Liderança Gerencial: Uma análise com base na motivação e Gestão de Pessoas. Revista Científica Multidisciplinar Núcleo do Conhecimento. Ano 05, Ed. 04, Vol. 07, pp. 26-32. Abril de 2020. ISSN: 2448-0959, Link de acesso: https://www.nucleodoconhecimento.com.br/administracao/liderancagerencial

\section{RESUMO}

Liderar um grupo requer habilidades e competências gerenciais. Nesse sentido, o indivíduo que ocupa tal atribuição deve, indubitavelmente, obter relações interpessoais, bem como desencadear foco nos processos instituídos. Outrossim, a eficiência e eficácia, devem ser pressupostos indispensáveis para tal. Em retrato de tal afirmação, a presente pesquisa científica promoverá uma inquirição bibliográfica acerca da gestão de pessoas, tendo como base a liderança gerencial. Ao longo da construção textual lógica, haverá uma abordagem sobre a conceituação de liderança e gerência, bem como análise minuciosa no que tange a relação da temática anteriormente mencionada, atrelada à motivação e gestão de pessoas. O presente estudo ajudará positivamente no aspecto analítico gerencial, uma vez que demonstrará a qualidade, eficiência e resultados intrínsecos ao direcionamento de como os conceitos dentro da perspectiva bibliográfica correlacionam-se diretamente de forma estrutural e prática, ressaltando a importância da sua aplicabilidade de forma

\footnotetext{
${ }^{1}$ Pós-graduado em Direito Militar pela União Brasileira de Faculdades - UNIBF. Pósgraduado em Gestão de pessoas e liderança pela União Brasileira de Faculdades UNIBF. Bacharel em Ciências Náuticas pelo Centro de Instrução Brás de Aguiar CIABA.
} 
conjunta para lograr êxito no objetivo, seja ele gerencial, motivacional ou mesmo para gerir pessoas.

Palavras-Chave: Liderança Gerencial, motivação, Gestão de Pessoas.

\section{INTRODUÇÃO}

De acordo com os estudos desencadeados por Robbins (2009, p. 154), podemos compreender liderança "como a capacidade de influenciar um grupo em direção ao alcance de seus objetivos". Sob tal afirmativa, iniciamos abordando um estudo que obteve a responsabilidade de tentar definir de forma sucinta o significado de liderança. As analises e discussões pautadas na presente pesquisa, correlacionadas diretamente ao aspecto de liderança gerencial, têm sido acentuadas nos últimos anos. Em consonância, com a informação parafraseada supra, acredita-se que um líder, de fato, possui dentre suas habilidades, a competência de direcionamento com direção a um objetivo, bem como o mesmo deve basear-se em aspecto que tem como subsídios a motivação e gestão de pessoas.

Ademais, cabe salientar que a significação da referida palavra é multidisciplinar e transversal, uma vez que pode ser mencionada e associada a aspectos que dialogam com diversas áreas do conhecimento. Existem múltiplos conceitos a respeito de liderança, afinal, deve ser levado em consideração que os líderes são pessoas plurais com especificidades convergentes e divergentes. Logo, a individualidade influenciará no modo de caracterizar o líder ao qual foi definido como objeto do referido estudo. Nesse sentido, obtemos o estilo de liderança que "[...] remete à maneira como os líderes se comportam e o que usam para controlar o comportamento dos seus liderados" (BANOV, 2008, p.31).

Nos estudos desencadeados por Bergamini (2009) observaremos enfoque de liderança, que se correlaciona dentro da perspectiva motivacional, acerca da valorização e aceitação do comportamento do líder por parte de seus seguidores, que estão ligadas à percepção do comportamento, não somente de uma fonte imediata de 
satisfação, bem como de recurso instrumental de peso que viabilizará futuras satisfações motivacionais que serão atingidas.

Portanto, abordaremos com mais profundidade em diálogo com os diversos autores acerca da importância de se ter uma boa e sólida base gerencial, assim como daremos enfoque no que tange a gestão de pessoas, onde a motivação fomenta na realização profissional tanto dos colaboradores, como da própria empresa.

\section{LIDERANÇA GERENCIAL: UMA ANÁLISE COM BASE NA MOTIVAÇÃO E GESTÃO DE PESSOAS}

De acordo com Cartwright; Zander (1969) a liderança é um motor impulsionador de seus liderados ou colaboradores. É através deste líder e seus atos que são gerados motivações dentro de uma organização. Essas motivações levam os liderados a atingir suas metas de maneira mais eficaz. O exercício do ofício de liderança requer inteligência, pois apesar de ser um oficio de um líder em específico, não poder ser descartada a coletividade do meio organizacional, onde vários fatores serão importantes para gerir uma organização.

Outro fator de suma importância é de como o líder de uma organização lidera seus subordinados, pois a maneira com que se dá essa liderança é capaz de estimular, bem como desanimar uma equipe como um todo. Portanto, a característica de como um líder atua em relação aos seus subordinados, em suas tomadas de decisões têm caráter decisório no caminho em que a organização andará, seja ela boa ou ruim. Ou seja, as relações interpessoais devem ser levadas em consideração, pois são justamente essas relações que determinam, em muitos casos, o clima da organização e define seus frutos.

Liderança trata-se de comandar, liderar, gerir determinado grupo de pessoas dentro de um meio organizacional, a fim de obtenção de resultados para uma empresa. $\mathrm{O}$ líder deve estar capacitado e preparado para lidar com situações cotidianas, bem como enfrentamentos de desafios constantes no dia-a-dia da empresa. O cargo de gerir ou liderar uma organização requer muitos esforços, até mesmo por ser um cargo 
que atua diretamente com a pressão, resultados satisfatórios, bem como todo um contexto de relações interpessoais com seus subordinados, colaboradores do meio interno e externo.

Liderar uma organização requer não somente ter ou desenvolver boas relações interpessoais, como também requer consciência das alteridades inerentes aos seres humanos, que devem ser respeitadas acima de tudo, para que assim haja um convívio harmonioso dentro e fora das organizações. Tendo em vista os comportamentos, anseios, medos e aflições de seus liderados, é de suma importância que o líder saiba trabalhar com as presentes questões, buscando não somente os resultados, como também ser perceptível dos acontecimentos da equipe, bem como saber individualizar cada colaborador, sabendo que cada um possui suas especificidades, sejam elas por crenças, modos de agir e pensar e costumes.

Acerca da contextualização de liderança, Robbins (2009) afirma em sua obra que liderar requer a capacidade de influenciar um grupo em direção ao alcance dos objetivos de determinada empresa. O mesmo dialoga sobre não se buscar somente uma boa interação em equipe, como também a capacidade que o líder deve ter manter-se na influência de seus liderados.

Em consonância, para Lacombe (2005) o líder não é gerente no sentido formal da palavra, e sim alguém que é o responsável pela realização dos objetivos de determinado grupo ou equipe.

Para Banov (2008, p.31) , "o estilo de liderança remete à maneira como os líderes se comportam e o que usam para controlar o comportamento dos seus liderados". Vejamos três características dos estilos de liderança segundo Banov (2008):

Autocrática: É caracterizada pelo autoritarismo individual do líder, também chamada de liderança autoritária. O líder fixa normas e as impõem, sem necessidade de opinião de seus subordinados. Tem uma postura altamente diretiva, só impulsionada pelas realizações de tarefas, onde as mesmas são planejadas por técnicas sem deixar espaço para a 
criatividade e a participação do grupo liderado. Tornando-os assim, essencialmente frustrados $\mathrm{e}$, consequentemente favorecendo um lugar de trabalho propício à tensão, ao stress e à desmotivação do liderado;

Democrática: O líder propõe a participação de todos os departamentos, em debates em prol de todos os que compõem a organização. Possibilita a integração, o desenvolvimento de providências e técnicas para atingir o objetivo esperado. Apoia seus liderados, desenvolvendo laços de amizade e cordialidade pra com os mesmos. O líder tenta ser um membro igual e na mesma posição dos elementos do grupo. Esse tipo de liderança promove um maior engajamento das pessoas, uma vez que elas se sentem motivadas e importantes para execução de tarefas e objetivos da empresa. Produz maiores resultados, atribuídos ao bom relacionamento interpessoal entre o líder e os subordinados;

Liberal (laissez-faire): Nesse caso, a atuação do líder fica muito reduzida, há liberdade para grupos e indivíduos tomarem decisões independentes quer o líder saiba ou não. Não há imposição de regras, o líder não é respeitado. A execução das tarefas é realizada pelo próprio grupo, sem que haja participação do líder. Esse ambiente favorece o desrespeito, a confusão, a impunidade, onde a falta de uma voz ativa que impulsione os processos, determine funções e resolva conflitos que culminam no fracasso de qualquer organização.

Portanto, como podemos observar ao longo das entrelinhas do presente estudo, existem diversas ideias, de distintos autores acerca da liderança gerencial no que tange à motivação na gestão de pessoas. Tal fato foi perceptível através das análises em diferentes obras. Um dos pontos imprescindíveis é justamente sobre a importância e poder que têm um ou mais líderes dentro do meio organizacional, todavia, não se pode descartar que, apesar das inúmeras responsabilidades que possui, o líder dentro deste contexto, também é um membro que constitui uma equipe, e que, apesar da sua posição em meio a tantos adjetivos que foram denominados ao longo dos anos e da história organizacional, o líder não está isento de erros e acertos. 
Sabe-se que um bom líder motiva seus colaboradores, encoraja e é o suporte para diversos conflitos e problemáticas no que tange ao meio empresarial. Porém, existe o líder que também adoece seus colaboradores devido a sua má gestão, e é justamente importante que se avalie e leve em consideração que dentre a imagem de autoritarismo que foi atrelada aos gestores no decorrer dos anos, no cenário atual ocorre mudanças a todo momento e podemos observar que o que ocorre na atualidade, é justamente a mudança de postura de gestores muito mais adeptos a ouvir opiniões, dialogar, e através de um bom convívio corporativo e organizacional tem-se a motivação de uma equipe como um todo.

\section{CONSIDERAÇÕES FINAIS}

Conforme demonstrado nas análises anteriormente destacadas, o conceito de liderança perpassa por várias perspectivas historiográficas que nos permitem desencadear diversas concepções a respeito de um único termo. Entretanto, se faz necessária, a análise propiciada em face dos autores que direta ou indiretamente abordaram a temática a fim de demonstrar que liderança gerencial, em sua forma conceitual, está intrínseca a ideia de motivação e gestão de pessoas.

Cabe ainda destacarmos, que esses mesmos processos de análises e de conceituação supramencionados, são elementos indispensáveis dentro do processo de liderança gerencial, uma vez que ajudam o mesmo a lograr êxito na perspectiva de objetivos lançados.

Desse modo, ante as análises bibliográficas e discussões propostas nesse texto, pode-se observar que o objetivo de discussão a respeito das significações de liderança bem como de demonstrar a sua relação para com os pilares motivacionais e de gestão de pessoas estão indissociavelmente concluídos. O que torna a pesquisa indispensável para o olhar mais interdisciplinar e transversal, uma vez que promove a demonstração da relação mútua entre conceitos distintos. 


\section{REFERÊNCIAS}

BANOV, Márcia Regina. Psicologia no gerenciamento de pessoas. São Paulo, Atlas, 2008.

BERGAMINI, Cecília Whitaker. Liderança: administração do sentido. 2. ed. São Paulo. Atlas, 2009.

CARTWRIGHT, Dorwin; ZANDER, Alvin. Dinâmica de grupo: Pesquisa e teoria. São Paulo: Editora Herder, 1969.

LACOMBE, Francisco José Masset. Recursos Humanos: princípios e tendências. São Paulo, 2005.

ROBBINS, Stephen Paul. Fundamentos do comportamento organizacional. São Paulo: Pearson Prentice Hall, 2009.

THOMPSON, Paul. A voz do passado - História Oral. Rio de Janeiro: Paz e Terra, 1992.

Enviado: Abril, 2020.

Aprovado: Abril, 2020. 